the energy in the in-phase mode, which is just the reciprocal of the matching condition for the trans. mitting case. However, application of this condition does not preclude the reflexion of energy, as it would in a simple feeder system.

In a radar application described in detail elsewhere ${ }^{1}$ this principle is extended by the addition of the feeders, shown dotted in the figure, giving a feeder bridge having four arms each $\lambda / 4$ long. By this means the energy in both modes (phase and antiphase at $A 1$ and $A 2$ ) can be absorbed, one mode into each of two receivers, the array then giving two polar diagrams simultaneously and quite independently into the two receivers. In such an arrangement neither receiver absorbs any power which could have reached the other receiver, even if that had been the only receiver present, but receives only energy which would otherwise have been re-radiated by the array.

Department of Physics,

C. H. Westcots

The University,

Edgbaston,

Birmingham 15.

Feb. 21

${ }^{1}$ Westcott, C. H., Wireless Eng., in the press.

\section{Spiral Cracks in Glass Tubing}

Dr. J. J. HopFIELD's description of spiral cracks in glass capillary tubing ${ }^{1}$ reminds us that similar cracks were observed some ten years ago with thinwalled tubing, during the development of 'flashed' sodium-resistant glasses. The tubing in question was a conventional soda-glass, about $5 \mathrm{~mm}$. in external diameter and rather less than $1 \mathrm{~mm}$. in wall thickness, flashed internally with a thin layer of rather weak sodium-resistant glass. Specimens of such tubing in which the expansions of the two glasses were not sufficiently closely matched developed, soon after drawing, spiral cracks. The pitch of the crack increased towards the end of the stick of tubing, as in the specimen described by Dr. Hopfield, and tended to become infinite. In addition, the slope of the spiral varied throughout each turn in a regular manner. Cracks of the type described were only found in tubing having very high strain between the flashing and the base glass, the circumferential tension in the flashing glass corresponding to a stress of about $200 \mathrm{kgm}$. per sq. cm., a figure of the same order as the average breaking stress of the glass.

B. N. Clack

Research Laboratories,

General Electric Co., Ltd.,

Wembley.

Jan. 24.

${ }^{1}$ Nature, 158, 582 (1946).

\section{Friction and Wear}

IN the literature of friction it has been generally assumed, often implicitly, that there is no causal relationship between wear and friction. Schnurmann ${ }^{1}$ has shown that the results of measurements of static friction on naked cadmium surfaces at temperatures down to $-100^{\circ} \mathrm{C}$. indicate that abrasion cannot be the only factor responsible for the elementary mechanism of friction, and that an essential part is played by deformation. The following treatment, however, provides direct evidence for this lack of a causal relationship. It is shown that the work involved in that portion of the abrasion which actually results in wear is a negligible proportion of the frictional work.

The amount of work required to abrade material from the bearing surface will be a maximum if this material is all removed as single atoms, and this maximum amount of work may, therefore, be calculated from thermochemical data leading to the heat of atomization of the materials involved. If the frictional force operating during a wear determ. ination is measured, we can then calculate both the total frictional work and the maximum work necessary to produce the observed amount of wear.

For a composite material containing 69 per cent by weight of calcite and 31 per cent by weight of an $o$-cresol formaldehyde resin of approximate empirical formula $\left(\mathrm{C}_{8} \mathrm{H}_{8} \mathrm{O}\right)$ tested against mild steel with a normal pressure of $50 \mathrm{lb} . / \mathrm{sq}$. in. at a speed of $50 \mathrm{ft} . / \mathrm{sec}$., the highest wear recorded corresponded to abrasion of $1 \mathrm{gm}$. for the expenditure of $726 \mathrm{kcal}$. of frictional work. The approximate heat of atomization of the material may be derived from the published values of the heat of formation of calcite, the heat of combustion of $o$-cresol with allowances for the additional atoms and bonds involved in the resin, and the heats of combustion and of atomization of the elements involved.

The heat of atomization of $1 \mathrm{gm}$. of the material is thus found to be $10.6 \mathrm{kcal}$., or 1.4 per cent of the total frictional work done. It follows, therefore, that the proportion of the frictional work to be ascribed to this abrasion process is probably several orders of magnitude less than 1 per cent, when allowance is made for the abrasion of particles considerably larger than single atoms.

The wear of the steel bearing-member was not measured in the above work and was not allowed for in the calculation. It was measured in another experiment in which it was known to be very much larger, and even in this case a similar calculation showed that it could not account for more than 1 per cent of the total work done. The above conclusion is therefore not affected.

In order not to prejudice the argument, high values have been used in the thermochemical calculation for those quantities the true values of which may still be open to question, for example, the latent heats of vaporization of calcium and carbon.

Ferodo Ltd.,

E. J. W. WhITtakeR

Chapel-en-le-Frith, Stockport.

Feb. 18.

${ }^{1}$ Schnurmann, R., Proc. Phys. Soc., 53, 538 (1941).

\section{Control of Low-Temperature Injury in the Victoria Plum}

IT is well known that many kinds of fruit and vegetable after picking may be damaged during storage at low temperature above the freezing point. The phenomenon has been widely studied, and there is a considerable literature on the low-temperature injury relations of the apple, plum, peach and grapefruit. That the conditions known as low-temperature internal breakdown of the apple and plum, as well as woolliness of peaches and pitting of the rind of grapefruit are the final and visible result of a series of 